\title{
Jakob Leupold's Imaginary Automatic Anamorphic Devices of 1713
}

\section{Bennett Gilbert}

To cite this article: Bennett Gilbert (2019) Jakob Leupold's Imaginary Automatic Anamorphic Devices of 1713, Media History, 25:2, 127-144, DOI: 10.1080/13688804.2016.1266240

To link to this article: https://doi.org/10.1080/13688804.2016.1266240

册 Published online: 17 Dec 2016.

Submit your article to this journal ๘

山 Article views: 39

View Crossmark data \lceil 


\section{JAKOB LEUPOLD'S IMAGINARY AUTOMATIC ANAMORPHIC DEVICES OF 1713}

\section{Bennett Gilbert}

In 1713, the scientific instrument-maker Jakob Leupold published designs for three machines were the first attempt to design machinery with internal moving parts that replaced human agency in creating original images. This paper first analyzes his text and engravings in order to explain how he proposed to do this, given contemporary materials and command of physical forces. Next, it characterizes the devices as a transition from concepts of incision to concepts of mirroring, taken as models of the history of mechanical reproduction. And finally, Leupold's replacement of the sighting grid with differential gears points to a set of problems appearing in contemporary philosophy represented in Rococo artistic production of this period as well. Taking the proposed devices in context, they help to theorize the complex notions of creative activity in Rococo visual culture. Taken as an episode in the history of communications, they instance the development of conceptions of personhood and of physical forces at stake in the invention of automated media.

KEYWORDS anamorphosis; automation; idealism; media archaeology; mechanical reproduction; Rococo

\section{I}

The first published plan for automating the creation of images has hardly been appreciated even though it was made by the most famous scientific instrument-maker of his day, Jakob Leupold (1674-1727). He tried to automate the making of anamorphosed images. Anamorphosis is the artistic practice of distorting a perspectivally correct image along consistent geometric lines in such a way that it is not legible except when reflected in a mirror or seen from a vantage point that corrects the distortion by restoring one-point perspective. Artists used the technique to create single-sheet drawings and engravings or small canvases, such as, for example, an undated (probably seventeenth- or eighteenthcentury British) playful anamorphic image of Venus ${ }^{1}$ and a seventeenth-century 'hidden' anamorphic portrait of Charles $\mathrm{II}^{2}$ as well as impressive spectacles such as anamorphed oil portraits of three saints, each of which is visible alone from a different angle, ${ }^{3}$ and a 65-foot long fresco St. Francis of Paola at Santa Maria dei Monti in Rome. ${ }^{4}$ The 'motor' of the devices that Leupold proposed in 1713 to anamorphose images was a pair differential gears that replaced the grid used by the artists of these and most other earlier perspectiveproducing apparatuses. The gears were intended to do the job of the artist, moving her artistic control and manual operations one step further away from her materials by interposing a mechanism for producing the anamorphed version of a given image.

This mechanism did not immediately present a new vista of cultural production in multiples as the technologies for reproducing texts and images that flourished from the 
mid-fourteenth century onwards had done, and yet it was not merely one more in the series of labor-saving mechanical aids for artists. What provokes interest today in Leupold's devices, published during a period of sophisticated reflection on mechanistic philosophy, is the fraught position of the artist's creative power in the face of the mechanization of the media of human expression. Automation, which seems so helpful and logical, often leaves people feeling that they are struggling with a threatening and overwhelming force and are in a situation that requires anxious compromises with the determining force of their rational machines. Responses to the benefits and losses from automation are part of the long and difficult connection between persons and objects. Without his intending it, Leupold's plans suggest some of the anxieties we now see as characteristic of an age of automation and as central to Western intellectual and political life. At the same time they portray a checkmate in this conflict of a character peculiar to the first quarter of the eighteenth century. Like other aspects of European culture in the period we now call the Rococo, Leupold's inventions suggest a deeply tense balance in the conflict of conceptions of personal agency with the Cartesian and Newtonian concepts of the deterministic, closed, and mechanically balanced cosmos. In this paper, I will place Leupold's efforts to invent automated production of anamorphosed images at the intersection of the histories of media and of automation in general and in the moral universe of the Rococo.

Historians of visual culture generally begin accounts of anamorphosis at Hans Holbein's stupendous anamorphed skull in The Ambassadors of 1533, along with references back to Albrecht Dürer or even to Leonardo, and then drop it after the heyday of artistic interest in anamorphosis during the time of Gérard Desargues (1591-1661), Emmanuel Maignan (1601-1676), and Jean François Nicéron (1613-1646). Because anamorphosis 'presumably went out of fashion' by $1700^{5}$-meaning no longer interesting to scientists and artists but more widely known as a toy-one is not surprised to find that few historians have discussed Leupold's devices, nor has anyone considered them as an attempt to design true automation of image fabrication. The greater part of media archaeology starts its work at 1740 at the earliest, more often at about 1790. Every one of the accounts published in the flagship collections and journals that have established disciplinary media archaeology in the last two decades skips from the end of the seventeenth century up to pre-Revolutionary or Revolutionary Europe after $1789 .{ }^{6}$

By and large, media and communications historians rigorously seek thorough-going materialist, though speculative, accounts of the relations within their subject-matter of humans to machines and to other objects. Aiming to resolve the agonism between human and machine, media theorists and historians often rely on some version of systems or network theory. The most extreme version in the field is that of Friedrich Kittler (1943-2011), followed by Lev Manovich and others, which holds that human consciousness just is the data driven by and drifting in our forms of communication and that the necessary tendency of the machinic is to take knowledge away from our control into its own. ${ }^{7}$ The radical position of Kittler shows the tendency of network theory in some media archaeology, even under more moderate impulses, to find reasons to deflate notions of human autonomy. As an instrument of a materialist and determinist point of view, network theory regards the desire to automate as the self-making drive of accumulated information, first as heaps of words and numbers inscribed on paper and later as droves of data. 
The network most often, but not always, grows in the manner requiring least friction and most efficiency, although in the long run every failure and mistake remain a part of every subsequent synchronic state. As a consequence, each bit of sediment is said to be re-mediated. Sometimes this is called 'the doubled logic' of technological innovation; in truth, it is no different from all other movement of the new from the old in history. When described as a consequence of network growth, the notion of doubled logic underlies the insistence by media archaeologists on the presence of past technologies in the present. However, if every medium re-mediates its predecessor media, at least one major reason it does so is because the deepest problems of the self that the media express never are dissolved and never end. The aspect of personhood that viewing ourselves as nodes in a network or that regarding our consciousness as fluctuations of voltage puts at stake is not as much an epistemological problem as it is a moral problem. The side of subjectivity that would be lost under this view is moral agency. The example of Leupold's imagined invention, as a chapter in the history of media, will, as I see it, help to show that network theory does not finish off the deep problems of personal will and moral agency. Instead, it drives us to consider how the distress that automation provokes, especially at the moment of invention, from out of its moving parts, concerns the moral universe of the operator rather than the ontology of the operator and machinery. This is one of the ways in which the history of communications can pursue issues that are both historical and philosophical, as I shall do in probing the implications of Leupold's proposed devices.

In examining this issue in Leupold's tract, I propose also to enrich the binary of human-machine by a new binary of concepts of human production that intersects it in the history of reproductive media. This binary comprises the two groups of techniques I call incision and mirroring. These terms both describe manual operations and also are metaphors for complex groups of ideas and feelings associated with the technical practices. Incision includes reproduction by impressing, scratching, or otherwise entering a copy-image into a substrate, such as paper, metal, and stone. Mirroring includes reproduction by reflection of light without visible mechanical operations in such media as photography, cinema, and digitization. Both have a chaîne operatoire by which persons are deeply entangled with objects and causality, but behind this commonality lies an important group of differences. Each relies on a different metaphor that might in turn reveal deep notions of epistemic and moral authority. By applying it to Leupold's proposed machines, I hope to develop the scheme of incision and mirroring metaphors as a means for probing these concepts in the history of the storage and diffusion of knowledge.

With regard to the contemporary context of Leupold's work, the search for personhood in Western culture of the first quarter of the eighteenth century is not often enough recognized by scholarship. We will see the issue first in terms of the contradictions and tensions in Leupold's technical plans, then through the schema of incision and mirroring, and finally in terms of the broader situation of European thought in the Rococo context.

\section{II.}

Leupold published his ideas in Anamorphosis mechanica nova ... printed 'at the author's expense' in Leipzig by Immanuel Tietzen, 1713, a quarto of four unpaginated 
leaves plus three folding engravings. ${ }^{8}$ The copy of this pamphlet held by the Beinecke Library, Yale University, which is the copy examined for this study, is bound with Leupold's published instrument catalogs of 1720 and 1722 (from the same printer), a manuscript catalog of instruments for sale by one Michael Deffeld of Ulm, ${ }^{9}$ plus one other pamphlet by another author describing an instrument for sale. ${ }^{10}$ (Among many other interesting instruments, Leupold advertised a 'Machina Arithmetica' in the 1720 catalog $^{11}$ and a device for anamorphing images in the 1722 catalog. ${ }^{12}$ ) None of these three devices for anamorphosis appear in the work on which Leupold's historical fame is based: his Theatrum Machinarum (Leipzig, Zunkel, 1724-1735 and 1788) in 11 folio volumes devoted largely to machines and instruments for hydraulic and liquids engineering-the last of the line of lavishly illustrated machine books that began in the Renaissance. It was the summa of a life spent as an inventor, an engineer, a tradesman, and a public official in Leipzig from 1696 until his death.

Leupold's text is slender. For each of the three machines it includes (1) a two or threeline introduction, (2) a descriptive list of its parts, and (3) some practical remarks on its use. At the end of the pamphlet he mentions some of his published predecessors in a brief bibliography and of course repeats the title-page instructions as to how to buy the devices. The instructions for using his three 'new' anamorphic machines are keyed to the three engravings by the figure numbers and by letters designating every part. As the title advertises, each machine uses a different means to project an anamorphic image (Figures 1-3) from a source image, which he calls the 'prototypon.' In the first machine, he intends the turning motion of a cylinder to communicate the lines of the source image (of a monkey) to be communicated to an armature by the turning of a cylinder to which the source image is attached. In the second, Leupold proposes that the armature turning around a conical core will incise the source image (of a chicken) in a widened, distorted version at the periphery. The third device allows the widest variation of results: an operator moves the inscribing point through a groove in a long wooden rod to a spot on a scale at which the incisor distorts the image (of a maltese cross) to the chosen degree.

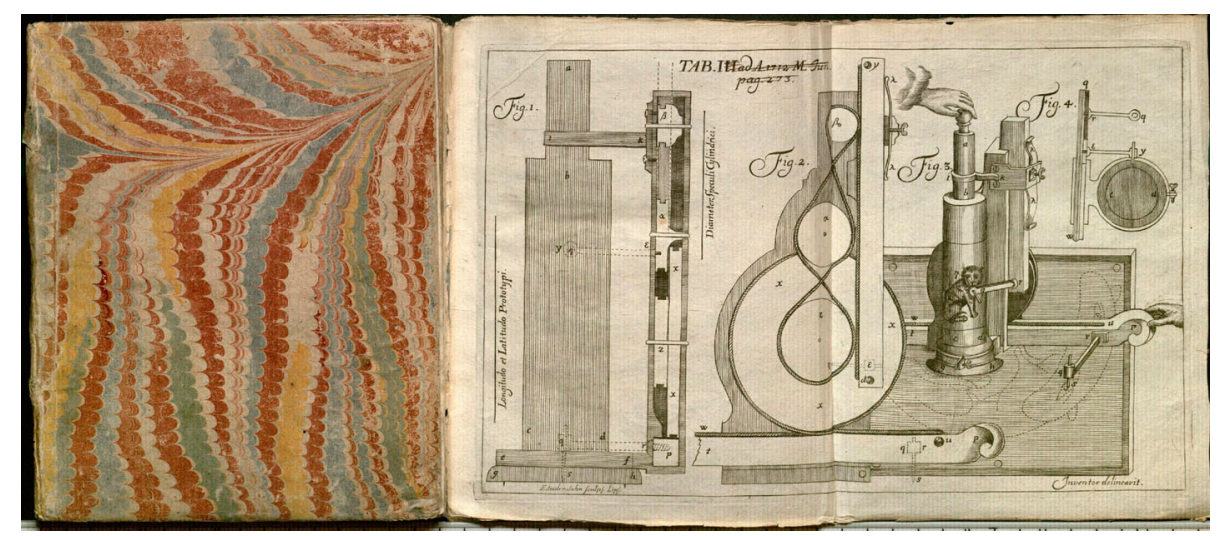

\section{FIGURE 1.}

Leupold, Anamorphosis Nova (1713), tab. I (mislabeled as 'III' and corrected by an early hand). The James Marshall and Marie-Louise Osborn Collection, Beinecke Rare Book and Manuscript Library, Yale University (Osb pc 235) 


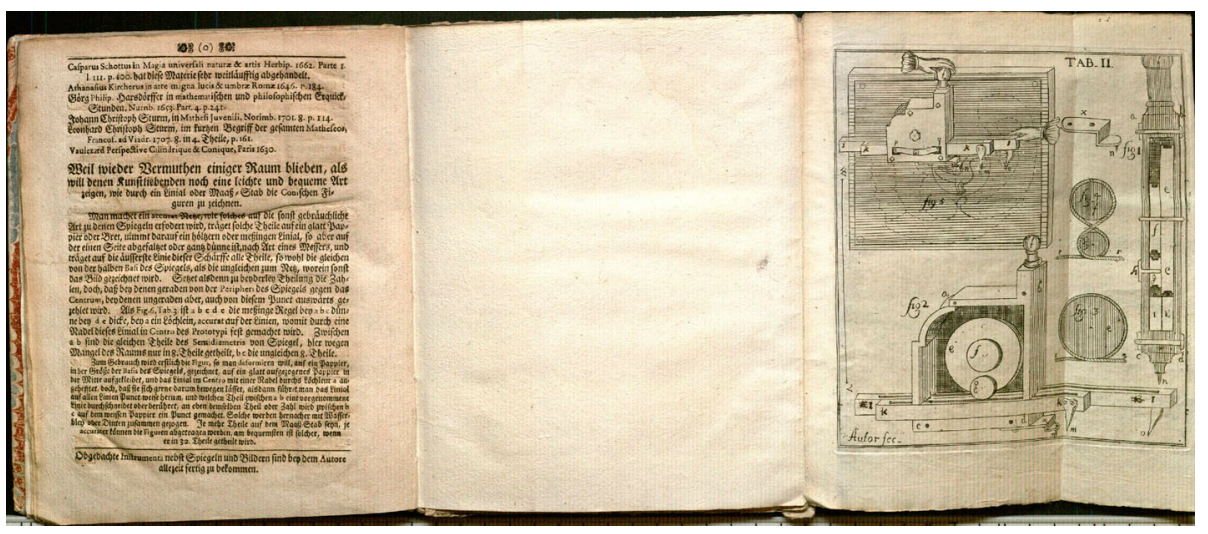

\section{FIGURE 2.}

Leupold, Anamorphosis Nova (1713), tab. II. The James Marshall and Marie-Louise Osborn Collection, Beinecke Rare Book and Manuscript Library, Yale University (Osb pc 235)

All three printed descriptions state a basic mechanical principle and include a procedure for applying this principle to production. The base principle of all three is this: the motion that a smaller wheel or gear communicates to a gear of larger diameter by a rope, through which the former turns the latter, will, guided by the human hand, accurately distend (that is, anamorph) the prototypon into the desired distorted inscription that the larger wheel produces. Leupold illustrates the pairs of stacked differential gears by front views and by cross-sections of their housings. Each system of image creation requires (1) a receptive point; (2) a communicating relay; and (3) an incising point, or incisor (Spitze) that punctures or draws the anamorphed pattern into paper. ${ }^{13}$

Although the differential gears can in theory provide accurately altered images, Leupold seems to have recognized that the mechanical communication of these distended

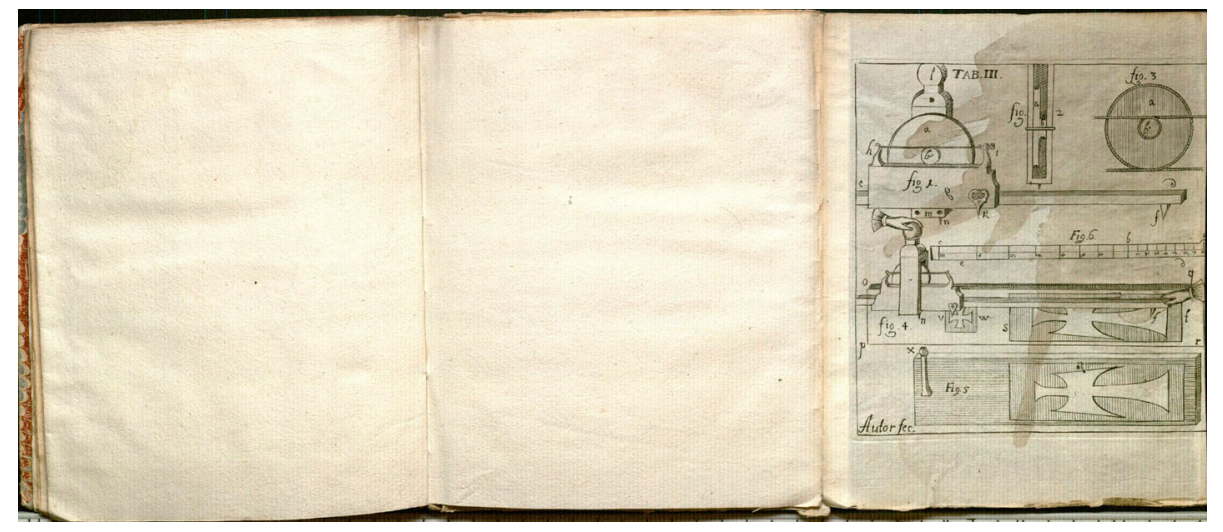

FIGURE 3.

Leupold, Anamorphosis Nova (1713), tab. III. The James Marshall and Marie-Louise Osborn Collection, Beinecke Rare Book and Manuscript Library, Yale University (Osb pc 235) 
lines to an incisor is at best imperfect without extensive guidance of the inscribing by the operator's eye and hand. And yet the hands he illustrated are small and inert, conveying a less forceful impression than the detached hands in the plates illustrating the works of Nicéron and Maignan, much less the complicated bodily labor of the artist whom Dürer portrays. All three devices require the operator to exert unrelenting pressure on the incising point, to hold the cylinder steady by downwards pressure, and even to move or turn the rod with the incising point around the cylinder. But Leupold leaves the problem of the operator, or technician, to the reader, referring to it in the text solely in vague terms, while the illustrations lack all representation of effort. ${ }^{14}$ Furthermore, nowhere in these plates does Leupold signify vision, either by metaphor or by metonym. The kinked curling lines representing the operations of vision in Nicéron and Maignan are absent in Leupold.

For both the labor and eyesight required by the process Leupold has supplied a fixed point from which both receptor and incisor extend. Tab[ula] III most fully realizes the indispensable job of this point, labeled as ' $n$.' It is disguised as the divided footing of the cylinder in Tab[ula] 1, labeled ' $g$ - $h$,' whereas in Tab[ula] II it is pivot ' $n$ ' which has a heavy job of asserting itself by lifting up footing 'c- $d$ ' through the contorted connecting plate, obliged to act as a lever and appropriately labeled ' $x$.' This axis point is necessary to enable communication of the diameters of the two gears to the two instruments. It would in fact do so, replacing the artist's laborious intelligence with a purportedly effortless or low-effort repetitive motion. This fundament of automated creativity appears on Leupold's pages about two and a half centuries before Andy Warhol recognized its full consequences.

Of Leupold's three proposed machines the first is in some ways the most provocative and intriguing. Like all these designs, it uses a pair of gears to convert vertical motion to horizontal motion. The plan for data input uses an engraved copper plate that is fastened by wax to the vertical cylinder that an operator turns. Leupold does not seem to consider whether curving the plate on the cylinder distorts the flat surface that printing an engraving requires, or that the engraved image on the plate is reversed from the image the plate prints. His plan also requires that the incised lines of the plate be deep and clear enough for the input needle to stay inside the grooves. Leupold of course was intimate with the art of engraving, but the requisite condition of the lines would obtain only for images pictured by simple outlines, without hatching, swelling lines, or lighter tones-like the picture of the cat used as the prototypon for this illustration. Finally, it is hard to imagine a system of connections among the incised lines that could guide the input needle through all the lines comprising the image if the needle simply bobs along with the rotation of the cylinder.

Here Leupold incorporates, albeit clumsily, the older technology of engraving into his machine. He uses it in a way that is unprecedented, so far as I know: the engraved plate remains but not for its conventionally intended function. Its productive element-the lines the engraver's tools have incised-are transformed to appear as if in a distorting lens. In the mid-fifteenth century artists used paste-paper images to make stereotypes from which copies could be struck, and it is possible that Gutenberg used stereotypes as well. $^{15}$ These practices are part of ancient techniques of casting and molding; but Leupold, abandoning these, seems to rely instead on a notion of mirroring of which he is not fully aware. This is a consequential distinction to which I will return. 
As this first device shows, Leupold envisaged automating the creative act more completely than anyone else before him whom we know of. Yet he lacked virtually everything we now know to be necessary for such a machine. By looking at the early successful graphic registration instruments invented by Étienne-Jules Marey (1830-1904) from 1868 onwards, we can see the kind of material Leupold did not have in early versions of the forms in which they were developed and used. ${ }^{16}$ These include, as Robert M. Brain has pointed out, materials that mimic organic structures, such as tubing sufficiently elastic to carry electrical impulses from the site of one function to the site of another just as nerves do. Rubber was unknown in Leupold's day, but Leupold might have used animal skin for this purpose. Marey used a diaphragm or tambour to stand in for skin. ${ }^{17}$ Also, Marey had, but Leupold did not have, electricity-the force that enables us to copy movement from one medium and register it in physical or digital documents. Lacking the imaging and transport capacities of electrical impulses, Leupold is forced to rely on human cognition and volition, try as hard as he might to suppress or to elide them.

Leupold's plans required mimicking certain human cognitive and motor functions. This mimicking characterizes a great deal of automation, especially in the early stages of a field of activity. Leupold had the shell of a notion-a capacious but empty husk-that bore fruit when ontological and material development later enabled suitable material invention. In the gap between Leupold's goal and the means of achieving the goal available in his workroom we can see that he was imagining part of automation as it was to come to be. He tried to displace human decision-making and much of the labor that the exercise of intelligence had hitherto required from the body for this purpose. The hands that crank the handles and guide the armatures in his illustrations signify this: they are motors without brains and without bodies. The result inched toward a domain of copying different from that of casting and molding-a newer domain, present but dimly and at the horizon. This small advance is the moment in the relationship of personal creativity and machinic power that Leupold's work suggests. One further aspect of Leupold's work - something absent, something he discarded and did not use rather than something new that he tried-helps to explain what I call this Rococo moment in the history of automation.

\section{III.}

The particular intended product of Leupold's machines is an anamorphed representation that is principally created not by the hand but by parts moving in accord with calculations. Neither hand nor established reproductive techniques (varieties of relief, intaglio, and etching) fully account for this method of the creation of graphic art, in which it is machinery that now immediately controls the images. The hand helps, but the possibility of its not being needed is now presented. The grid is gone, but arithmetic and geometric structure are more rather than less determinative. The inventor's abilities are chasing away the traditional contribution of the artist's abilities, manufacturing by mechanical means what hitherto had to be imagined wholly in the mind's eye. The operator-artist's hands pictured in the plates have a sort of job to do: a rote job of merely exerting pressure, a job that is not clearly illustrated but that clearly is on the way to being eliminated. Nonetheless, the plates suggest the presence of a person attached to the small hands, who appears as the 
creative intelligence of an inventor or a mechanic, such as Leupold himself, whilst the artist's tactile knowledge slides down the value scale of labor, demoted to turning knobs and 'controlling quality' in the manufacturing chain. A process here appears that was new at the time, although parts of it were familiar. The use of old parts in a new way in fact signals something strange about the process: it is intended to work as if the datum moves and alters itself, although it could not possibly do so with Leupold's technology. Instead of inventing these devices, Leupold could have used Scheiner's pantograph, invented in $1603,{ }^{18}$ had he wanted simply simultaneously to draw an isomorph; and there was no type of anamorphosis that the old techniques could not accomplish. The hand as he portrays it here is unknowingly conceived as a step-small, perhaps, but distinct-back from its use in previous perspectival devices. Strikingly, it is aided by no die, mold, burin, or graver. The process Leupold describes is more like mirroring than it is like incision.

In my research on concepts of the conceptual sources of the reproduction of text and images in the Occident I have been investigating an hypothesis that two principal streams of metaphor for human production-those that I referred to above-have informed the relevant conceptions. The first to suggest this binary scheme in print was, so far as I know, the brilliant medievalist Michel Camille (1958-2002). ${ }^{19}$ One of these streams is metaphors of incision, which includes punching, casting, molding, and all the impress of original into the material substrate of copy, governed by moral and veridical authority. The other is mirroring. Reflections in the mirror were understood from antiquity through the Middle Ages to be less material than production by impressed tools and were often associated with magic. This type of representation is profoundly tied to specularity on the part of a person, in whom it is mutable more according to subjectivity rather than in accord with material substrate. The mirror is the metaphor governing the diffusion of digitized data and images, in which the material touch of original to copy is not incised but is, rather, 'invisible' and without visible or tangible substrate. Although electronic processing and screen displays are in fact material, the events they represent are movements of light and electricity rather than of mechanical parts.

Now, incision and the mirror do not rigidly exclude one another either as techniques or as metaphors; and there are domains in which it is likely not possible to separate the two, such as that of acheiropoietic images. Mirroring is of course no less ancient a trope than incision, and the two metaphors frequently mingle. For example, Brunelleschi uses it as device and as concept right at the beginning of the early modern history of perspective. ${ }^{20}$ Leupold, too, mixes incision and mirroring when he shows that his apparatuses can punch a stencil to be used for pouncing, the process by which an artist forces a powder through stipple-produced holes configuring a design so as to provide a pattern on another surface. The long-term switch from incision to mirroring is merely incipient at this date.

Using this framework, we can say that Leupold's proposed production techniques were small, early, partial, and unconscious technological steps toward the increasing force of the mirror model of the artefaction of text and images relative to the incision model in Western representation, both prototypical and reproductive. The means by which Leupold arranges relaying the image to the incisor is more like that of a mirror manque than anything at all in the ancient lineage of casting techniques. Leupold does 
in fact prescribe the assistance of a mirror for his third device - the conical apparatus - and for the third one only ${ }_{i}^{21}$ but, again, the point is not so much the technology as the trends in the conception or metaphor informing production even when the latter does not fully realize the former. Leupold's anamorphic machinery envisions, just a very little bit more than its predecessors yet to a degree sufficient to command our attention, the creation of images by incision, and yet in the same stroke it requires some transfer without incision that is akin to the reflection in a mirror-in this case, a distorting mirror. Because their inventor did not have the technology for true non-incising production, the human hand must intervene so as to press the incisor down on the paper, as if incision were now only barely necessary, nearly done away with; and in the first device the most prominent incision technique of its day-engraving - is re-mediated, dis-empowered, and re-positioned to serve a wholly other conception.

Photography was at last to realize this conception more fully about a century later by making actual the transfer of light, as if in a mirror, and then fixing the light image. It was photography that freed the subject's range of perception into new, now familiar, forms. There were more tinkerers (stretching back into the eighteenth century) experimenting with proto-photographic techniques than there were canonical inventors, and we can class Leupold among the earliest of them. ${ }^{22}$ This context should also include the history of the automated graphic registration of information, the study of which has hardly commenced. ${ }^{23}$ Earlier graphic registration devices include Anselm de Boodt's 1609 use of a hodometer with a compass to punch holes in a strip of paper; and Christopher Wren's and Robert Hooke's unpublished weather clock of around 1663, which recorded atmospheric temperature changes.

In the third volume of his Theatrum Machinarum (1724) Leupold describes a universal meteorological recorder, called the plagiscope that is intended to inscribe measurements made by thermometers, barometer, and hyetometers (rain-gauges). ${ }^{24}$ In his anamorphic devices Leupold tracks the same goal, attempting to convert a circular motion that copies the traces of rectilinear motion into new and altered rectilinear form. Raindrops or heart-beats are so different from graphics that once they are measured the engineer needs only to convert one way of measurement of motion into another. But the anamorphosed image is the same sort of thing that the source image is: it has no intermediate form except that which is in the mind of the operator. The fineness of this mental intermediary requires greater control of operation than Leupold's materials allowed him.

It seems that Leupold attempted to transfer light, but of course this effort was frustrated because he had to contend with friction. Besides lacking an energy source other than human input, his insensitive materials cannot overcome the friction of registration points on the surfaces of either source or product. Leupold describes some of his attempts to control friction with rigid guides for rollers as well as other devices in volume one of the Theatrum Machinarum (1724). ${ }^{25}$ The successful way around friction in fact is, however, not by mechanical force but by electrical power and chemical processes, the true principles of which Leupold could not have known in 1713. Again, the failure of machinery brings unrealized conceptions to light. The ideas out of which the failed device was constructed show that at Leupold's moment the mirror metaphor of the reproduction of images, which used light rather than mechanical inscribing operations, could express the power of human agency and at the same time promise its substitution by automation. 


\section{IV.}

One part of Leupold's thinking by which he devised these inventions was his idea of dispensing with the sighting grid (netz) used in much of the prior history of perspectival devices. From the time of Dürer's famous first illustration of a device for drawing perspective in 1525 , most such devices illustrated in print or in manuscripts rely on a lattice or grid through which the artist looks or through which light is projected. ${ }^{26}$ From Alberti and Brunelleschi through Nicéron and Maignan, the grid is an important tool for monopunctual perspective, including anamorphosis. It expresses a notion of rationality belonging to perspectival conception and artefaction. Without it the artist's eye lacks a capable tool for the task of drawing in perspective. Also, Dürer, Maignan, and Nicéron all suggested the use of the grid in anamorphosing an image, which they considered a function derived from rendering an image in proper perspective. One reason to remove the grid is to replace it with a mechanism that does what the artist and the grid do together. To this end Leupold's gears are lashed to one another; but, huddling with their pivots, they almost fully exclude the artist, pushing her outside the brass and wood housings within which they spin. They point to mechanisms not yet invented in 1713 based upon forces not employed in full until more than a hundred years later. They point to a spot to be filled in and in this way are a straggling early thread of the changes in vision and perspective away from their Renaissance forms into the new forms to be associated with the technical and artistic developments of the nineteenth century.

The closest predecessor is the machine proposed by the influential teacher Ludovico Cardi di Cigoli (1559-1613) in a manuscript of c. 1610-1613 that though never published was well circulated in copies. ${ }^{27}$ Nicéron describes Cigoli's device as a 'machine catholique' or 'universel. ${ }^{28}$ But for Cigoli an image in perspective was correct and true. Although his machine could produce an anamorph, he seems not to have been interested in making a 'figure defformé et confusé en aparence,' in Nicéron's words. ${ }^{29}$ Whatever the capabilities of Cigoli's apparatus were, Leupold's proposed machines, besides being the first such devices in print, aim, as Cigoli's machine did not, to automate the alteration of an image.

Leupold's plan for a unified automated act rearranged input information in the process of registration on a document. To the extent that the artistic person was as much dominated by the grid as she was dominating nature, Leupold, perhaps like other inventors of automata, seems to have wished, if unconsciously, to free the agent by providing her with a means of more powerful domination of the field of vision, of production, and of personal expression. His removing the grid from the production of 'deformirte Bild' 30 separates anamorphosis from monopunctual perspective and moves the intelligibility of the information out of control of the spectator, who needs another device (such as a cylindrical mirror) or a key (e.g., the location at which she can return the image to its public, or intuitive, or original form). The ghost of the person in Leupold's plans-the artist partially disembodied in anticipation of a causal agent both freer and more efficient but that was not yet within the inventor's technical capability-is part of what grew to be an important conflict in later modernity: the conflict between subjectivity and documentality. ${ }^{31}$

In 1713 Leupold, as Gutenberg and his immediate followers among letterpress and engraving printers in the mid-fifteenth century had done through their laborious development of the screw-press and the roller-press out of predecessor machines, interposed an 
energy-transferring machine between the person and the document. ${ }^{32}$ Because the technology of printing was largely stable from about 1465 (with the adoption of the roller-press for engravings) until the early nineteenth century, no innovation in the graphic creation, storage, or diffusion of information between Gutenberg and Leupold accomplished this transformation in a new way-for example, not the first text indices in the 1480s, not increased production and management of printed texts in the $1490 \mathrm{~s}$, not clarified typographic layouts in the 1530s, nor the widespread use of engravings in book illustration (richer in information than woodcuts) in the 1550s, nor incremental improvements in press and paper and style. These and other tools that enlarged the epistemic base lodged in texts seem to have increased hermeneutic and humanistic subjectivity, tending toward the surer hold of a person on ideas and words, rather than to have threatened it. In Foucault's terms they increased the will to knowledge that constitutes subjectivity. In the resuscitation of the anamorphic image as a toy, as in all the optical games and instructional techniques of the eighteenth century, both the emergence of powerful empirical technology was forecast and deep fears of the power of documents to control and to distort life in the world were elided, diverted, perhaps pacified for a while. ${ }^{33}$ In Leupold's failed machine, partly because it combines anamorphosis with automation, we can see one early, hazy, distant sprout of the phantasmagoria of the individual and mass society in the next and succeeding centuries.

\section{V.}

By removing the grid from his devices Leupold moved the link between the way in which the mind creates and the way in which machines produce in a direction that is, in part, turned away from mechanistic causality as it was commonly understood around 1713. Unawares, he straggled toward seeking a source of action in the image itself rather than in tangible causes. His plans imply that direct use of the tool does not probe or reveal the inner content of the image so well as the use of tools to make other tools does. These other tools then probe further than our hands or eyes; they can do something that seems magical to people who look at the matter from within a mechanistic view of the universe. Inside of the objects we create-which is to say, inside ourselves, in our moral universe-lies another structure that looks strange to us, leading to a different level of experience.

His anamorphosing and automating attempts, taken together, adjust the relations of subject and object in response to the conflict their separation posed in contemporary thought. A brief and rough account of this conflict begins with Gottfried W. F. Leibniz (1646-1716). Leibniz, responding to problems in Descartes's metaphysics, Netwonian mechanics, and the Western logical tradition, saw the cosmos as a dynamic but perfectly calibrated infinity of interlocking operations inseparable from its creator. Dissatisfied with the elaborate typology of causalities that Leibniz's conception required, Bishop George Berkeley (1685-1753) radically reduced all natural forces, powers, and qualities to the will of God-cutting to the chase, as it were, past Leibniz's architectonic. Berkeley argued that we misunderstand the apparent mechanism of causality if we take it to be a contingent structure so vast and intricate that it presents us with the possibility of our non-existence, or even terrorizes us with annihilation; it is, instead, a divine plan that we, in our finitude 
and simplicity, read as physical causality. Its real substance, he holds, is not material; its real power, not the causality belonging to matter but the creativity belonging to spiritual beings. In the same decades, from about 1710 to the 1740s, Giambattista Vico (16681744) expanded a notion of our mental reflection to an amplitude at which it is adequate to history and must be understood as a force distinct from nature itself and thereby not subject to the overwhelming power of a mechanical cosmos.

Viewed in the framework of the first quarter or third of the eighteenth century, the notions of non-material and non-natural causal force that Berkeley and Vico employdivine creation for Berkeley and the stuff of human intelligence operating in the world for Vico-parallel a ground that was very fully expressed in the plastic arts of the Rococo. The highpoint decades of Rococo style ran from about 1700 to about 1740 , following the high tide of the preceding Baroque period and prior to the subsequent technological regime of the Encyclopèdie and the rationalist regime of neo-Classicism that from about 1740 onwards. Starting in about 1690-1700 craftsmen, artists, and architects began to alter Baroque style. Rococo style then flooded into Western arts and design-into the production of paintings, interiors, furniture, buildings, and beautiful objects of all kinds and through music and literature in varying degrees - in the subsequent decades, flourishing and then fading in different parts of Europe and the Americas until it submerged beneath a highly rationalistic and materialist classicism, led by Denis Diderot (17131784), that vigorously attacked it on strong philosophical and moral grounds.

Partly as a result of Diderot's critique, art historians conventionally have seen the Rococo as a variation of the favored phenomena of the Baroque; its definition, extent, and qualities are greatly disputed. ${ }^{34}$ More recent scholarship supports a different view. As a particular form of the idea that the human is uniquely endowed with creative potential, it burst past the towering hierarchies of Baroque vision and put the focus on atectonic visual effects that appear to flaunt the laws of natural mechanism in favor of free human creative expression. The enormity of the universe, the vastness of knowledge, and the terrors and comforts in nature-in short, the sublime of the eighteenth century-put the focus on what being a human person means in these circumstances. In an untheorized way Rococo style addressed this by attention to the situation of persons as creators. Leupolds's attempted automation of anamorphosis moves anamorphosis from a Baroque marvel into the contest of a Rococo compromise about human agency amidst a mechanical universe.

It is his rejection of the grid, or lattice, that links Leupold's mechanical imagination to Rococo style, and it also connects philosophical and art historical concepts to issues in automation. Of all the great motifs of Rococo decor-the shell, the mirror, the S-curve, and the C-curve, the pairing of white and gold, the palm tree, the raffle-leaf, the grotto, rocaille itself-the one least commented upon by scholars is one of the most frequent: the lattice. ${ }^{35}$ On walls and vaults, in wood and bronze, dominating palace, cathedral, and bibelot, Rococo architects and artisans-especially the stuccadors (stucco-workers) who created the surface decoration that architects wanted-squeezed, clipped, and twisted the grid. It was subjected to the demands of perception and of taste instead of subjecting perception and taste to its structuring of homogeneous and abstract space. In these deluxe objects and buildings the designers seemed to use their distorted latticework ornaments to attack and to subvert the control of nature by rational mechanics. In some parts of 
the consciousness of Western early modernity in the first quarter of the eighteenth century the benefits and the dangers that a mechanistic, reductive, and bureaucratic episteme represented by the powerful contribution of the grid to thought-from Descartes' $X-Y$ graphs toward the quantification and formalization of empirical knowledge-was subjected to active discursive debate and implicit artistic critique.

The apparatus devised by Cigoli and Scheiner had substantial renown and influence, whereas Leupold's pamphlet had little. Yet Leupold's machinery for anamorphosis is an example of the difficulties-growing in part from the pressures of mechanistic philosophy-within the Western conception of subjectivity at the end of the Baroque impulse. His removal of the grid reflects a critique, also expressed by the anamorphosis of the grid in the plastic arts of his day, of the mechanical world-system administered by single-point rational perspective. If anamorphosis had always been a critique of systematized knowledge, then Leupold's invention goes a step further: it shows us a mechanical engineer beginning to inquire into a different view of nature, in which both physical forces and human subjectivity were to be reconceived. ${ }^{36}$ Art historian Bret Rothstein points out that the artistic practice of anamorphosis 'probe[s] the contingency of human understanding. ${ }^{37}$ In the early modern period it squeezed something suppressed and something new as well out of images that, along with many other developments over the course of time, put representation into question. This reflected issues not only of what the machine does but also of what persons do. Leupold's steps toward turning an artist into an operator of machines suggest some of the anxiety about human personhood inside the drive toward automation. ${ }^{38}$ As if in a negative image, the missing efficient cause in his plans shadows questions of personhood and identity that rise when we contend with nature and when the knowledge gained in that contest develops into forms of registration and classification that we both resist and desire.

As a general principle of media history, the understanding of the human person that we gain through human and machinic forces is more important than the development of our technology. If the power of inscription has no foundation other than its interaction with material nature, its potential to re-order personal action and knowledge by registration can be calamitous. When we look closely enough to understand Leupold to be - just barely visibly — on the fine ledge of a domain in which machines create, or seem to do so, and while watching him withdraw mind, eye, and hand, even in very small measures, we can and must see, along with the gains, the distress that the losses cause. In Leupold's world and at his moment such fear of calamity, taking a large political form as state absolutism, was conceptualized as a crisis of knowledge by which our place in a world of mechanical causality and our extinction as moral agents were separated solely by a perilously thinning film of subjectivity. In the Rococo moment in the first decades of the eighteenth century this dark fear could be wished away in optimism, sensual joy, bounteous production, and the free development of forms. Leupold, neither natural philosopher nor artist but an engineer looking at the possibilities of machine power for image production, arrived at a situation of contradiction or, as I put it at the beginning of this paper, an uneasy stasis. Here in this small moral universe, even in the beginnings automated media, and particularly automated documentation, lay the conflict over the nature of human personhood. 


\section{Acknowledgements}

I am grateful to Prof. Thomas Luckett of Portland State University for his generous help in Rococo studies, to Damien Jack for editorial assistance, and to an anonymous reader for many valuable insights.

\section{Disclosure Statement}

No potential conflict of interest was reported by the author.

\section{Notes}

1. Unsigned, at the West Highland Museum, Fort William, UK. It can be seen both as a canvas and reflected in a cylinder at: http://artuk.org/discover/artworks/anamorphic-venus167682/search/keyword:anamorphic/view_as/grid/page/1.

2. Unsigned, at Tapley House, Devonshire, UK. The canvas can be seen at http://artuk.org/ discover/artworks/an-anamorphic-portrait-of-charles-ii-103812/search/keyword: anamorphic/view_as/grid/page/1

3. Undated, sixteenth to seventeenth century, in the Wellcome Library. All three views can be seen at http://artuk.org/discover/artworks/saint-francis-of-assisi-saint-francis-de-paul-andsaint-peter-penitent-126268/search/keyword:anamorphic/view_as/grid/page/1.

4. Unsigned, eighteenth century, fully displayed in a short film from the National Gallery (UK) on Youtube at https://www.youtube.com/watch?v=4aGWQOzHOJY A short film explaining early anamorphic techniques, with illustrations from contemporary manuals and examples made in 1991 by the Brothers Quay can be watched at https://www.youtube.com/watch?v= 4EfSmGSrF3w

5. Andersen, The Geometry of an Art, 611.

6. These papers include, among others: Couchot, "The Automatization of Figurative Technique," 181-92; Gitelman, "Introduction," xi-xxi; Manovich, "The Automation of Sight," 229-45; Tomas, Beyond the Image Machine, 11-40; and Zielinski's various works, notably Deep Time of the Media and "Modeling Media."

7. Parikka, What is Media Archaeology, 63. Kittler, in his Optical Media, 29-30, holds that we ought to think about our bodies, and therefore our experience and our selves, in terms of technological media and information rather than think of the media in terms of our sense of human personhood.

8. Jacob Leupolds, Mechanici zu Leipzig, Anamorphosis mechanica nova, oder, Beschreibung dreyer neuen Machinen: mit welchen sehr geschwinde und leichte, auch von denjenigen, so solcher Wissenschafft unerfahren, mancherley Bilder und Figuren können gezeichnet werden, dass sie gantz ungestalt und unkäntlich fallen, dennoch aber die ersten durch einen Cylanderdie andern durch einen Conischen- und die dritten mit einen flachen Spiegel oder gewissen Augen-Punct wiederum in rechter Gestalt und Proportion erscheinen, mit vielen deutlichen Figuren entworffen: auf Kosten des Autoris, bey welchen es im Nosocomio vorm RanstädterThore wie auch im kleinen Fürsten-Collegio bey C. Zunckeln zu bekommen. There are two recorded US copies: the Beinecke copy and a copy at the Adler Planetarium in Chicago (plus a photocopy of the Beinecke copy at the Getty Research Institute. The Adler copy is 
bound with the three parts of Leupold's Antilla pneumatica $(1707,1712)$, his 1718 illustrated machine catalogue, plus seven philosophical dissertations and two scientific dissertations from 1743 to 1752. There are also six copies in Germany, two in Great Britain, and one in Denmark.Plate ('Tab[ula]') I (mislabeling as plate III corrected in an early hand) is signed by Leupold as the draftsman ('Inventor delineavit') and by E. Andresohn of Leipzig as the engraver; plates II and III are signed by Leupold ('Autor fecit').Early references to this work include a preview, titled 'Machina anamorphotica ad deformandas imagines, a speculo cylindrico reformandas,' in the Acta Eruditorum for 1712, ed. Otto Meincke (Leipzig, Günther for Gross and Gleiditsch), 273 and the plate on 367; a detailed description by Alexandre Savérien, Dictionnaire universel de mathématique et de physique (Paris, Rollin and Jombert, 1753), 1.23-24 and plate 38, fig.s 265-268; and a brief description in Mathurin-Jacques Brisson, Dictionnaire raisonné de physique (Paris, hôtel de Thou, 1781), 1.92 (citing Savérien and wrongly giving the date as 1714).Modern references to this pamphlet include Andersen, "Geometry," 611-2; Baltrušaitis, Anamorphic Art, 155-7, fig. 122; Rink, "Jakob Leupold and his Theatrum Machinarum," 128, no. 2; and Stafford and Terpak, Devices of Wonder, 245, fig. 84, and exhibit catalogue entry no. 164 (Beinecke copy).Rink, 'Leupold,' includes a complete bibliography of Leupold's publications. Troitzsch, "Zum Stande der Forschung über Jakob Leupold," 263-86, is a comprehensive study of the early and modern literature to its date on Leupold.

9. I have found nothing on Deffeld, who describes himself as 'Mathematophilis.' I presume the manuscript is holographic. It lists instruments with prices, and it includes a drawing of the differential gears used in one of the anamorphic machines in a housing, directly copied from the engraved figure. As it is on a tipped-in piece of paper cut to size, larger than the leaf of the manuscript, and gently folded at the top to fit, the writer went to some trouble to include it.

10. Beinecke Library, Yale University, Osborn pc235.

11. f. 2 r.

12. This is item 1under 'Neue Optische Sachen' on f. $1 \mathrm{v}$, priced at 2 thalers, 6 groschen, described as using a cylindrical mirror and therefore probably is identical with the first machine described in Anamorphosis mechanica nova.

13. Tomas, Beyond, 180-5, following an idea from Gregory Bateson, is one of the few media historians to focus on the significance of the point of inscription.

14. ff. $2 v-3 r, 3 v$, and $4 r$.

15. The most comprehensive current survey is Fleischmann, Metallschnitt und Teigdruck; however newer scientific studies are under way although as yet unpublished. The issue of Gutenberg's possible stereotyping has been raised by the discoveries of Paul Needham and Blaise Augüera y Arcas, for which see Augüera y Arcas, "Temporary Matrices and Elemental Punches in Gutenberg's DK Type."

16. For Marey see Braun, Picturing Time: the work of Etienne-Jules Marey and also the short but incisive discussion by Daston, "Scientific Objectivity with and without Words," 276-9.

17. One element Marey and Leupold had in common is that they both used paper as the memory substrate for the registered result. See Brain, "Representation of the Line."

18. Invented by Christoph Scheiner (1573-1650) and first published in his Pantographice seu ars delineandi (Rome: Grignani, 1631).

19. Camille, "Before the Gaze," 209-11. 
20. Damisch, The Origin of Perspective, $61 \mathrm{ff}$. See also Carman, Leon Battista Alberti and Nicholas Cusanus, $122-9$ and $137-40$.

21. f. 4 r.

22. Leupold's inventions fit well as a dim pre-figuring of the developments later in the eighteenth century described by Batchen in his superb account of proto-photography, Burning with Desire, $106 \mathrm{ff}$.

23. Hoff and Geddes, "The Beginnings of Graphic Recording," seems to be the only general account of this subject yet published; Braun, Marey, 389 n. 42, gives a list of other papers that Hoff and Geddes wrote together on particular topics and events in the history of this kind of technology. Little has been done in this area since their work.

24. Hoff and Geddes, "Beginnings," 304-9 and fig.s 15-16, noting that it does not appear that Leupold successfully made this mechanism.

25. Section 238 as cited in Lockett, "Friction According to Jakob Leupold," 55-7. Volume one of Leupold's work is titled Theatrum Machinarum Generale.

26. Like the grid system for maps attributed to Ptolemy, the artist's grid-which was perhaps taken from the mapping grid-was a way to make space into uniform modules from which copies of images could be built. See Edgerton, The Renaissance Discovery of Linear Perspective, 111-23.

27. On Cigoli see Chappell, "Cigoli's Prospettiva pratica," 105-25 (New Haven: Yale University Press, 1997); Kemp, The Science of Art, 177-80; and Massey, Picturing Space, Displacing Bodies, 92-3.

28. Jean François Nicéron, La Perspective Curieuse (Paris, Billain, 1637; Langlois, 1652; and Du Puis, 1663), 130-3 (R1v-R3r) and tab. 37 fig. LXXIV and tab. 38 fig LXXV. The imposition is the same in all three editions.

29. Nicéron, La Perspective, 100 (N2v).

30. f. $3 v$.

31. Registration of identity, as Groebner, Who Are You? has shown, is associated with documents in early modern society.

32. A scribe's pen of course transfers energy, but it has no mechanism intervening between muscles and the inscriptor point.

33. See Stafford, Artful Science, 105. Stafford also discusses a text by Leupold on sign language (204-9).

34. On the question of the distinction between Baroque and Rococo, see my thesis, Some Neglected Aspects of the Rococo: Berkeley, Vico, and Rococo Style, 66-95

35. My claim that scholarship of Rococo style does not adequately treat the lattice or grid motif is based on study of the major catalogues of Rococo objects and books on Rococo architecture, too numerous to mention here, and on my reading of the theoretical literature on the Rococo. The works from this latter category that have most informed my observations include Bauer, Rocaille; Harries, The Bavarian Rococo Church; Minguet, Esthétique du rococo; and Weisgerber, Le Rococo Beaux-Arts et litterature.

36. For a view of anamorphosis as such a subversion or critique throughout its earlier history, see Clark, Vanities of the Eye, 90-6.

37. Rothstein, "Making Trouble," 119. 
38. Much of the recent literature on anamorphosis connects it to psychic drives and desires, based on Jacques Lacan's analysis of Holbein's anamorphosed skull. The source text is Lacan, Seminar XI.

\section{Bibliography}

Andersen, Kristi. The Geometry of an Art: The History of the Mathematical Theory of Perspective from Alberti to Monge. Berlin: Springer, 2007.

Augüera y Arcas, Blaise. "Temporary Matrices and Elemental Punches in Gutenberg's DK Type". In Incunabula and Their Readers. Printing, Selling and Using Books in the Fifteenth Century, edited by Kristian Jensen, 1-12. London: The British Library, 2000.

Baltrušaitis, Jurgis. Anamorphic Art. Translated by W. J. Strachan. New York: Abrams, 1977.

Batchen, Geoffrey. Burning with Desire. The Conception of Photography. Cambridge: MIT Press, 1997.

Bauer, Hermann. Rocaille. Zur Herkunft und zum Wesen eines Ornament-Motivs. Berlin: de Gruyter, 1962.

Camille, Michael. "Before the Gaze." In Visuality Before and Beyond the Renaissance: Seeing as Others Saw, edited by Robert S. Nelson, 197-223. Cambridge: Cambridge University Press, 2000.

Carman, Charles H. Leon Battista Alberti and Nicholas Cusanus. Towards an Epistemology of Vision for Italian Renaissance Art and Culture. Burlington: Ashgate, 2014.

Brain, Robert M. "Representation of the Line: Graphic Recording Instruments and Scientific Modernism." In From Energy to Information: Representation in Science, Technology, Art, and Literature, edited by Bruce Clarke and Linda Dalrymple Henderson, 155-177. Stanford, CA: Stanford University Press, 2002.

Braun, Marta. Picturing Time: the Work of Etienne-Jules Marey. Chicago, IL: University of Chicago Press, 1992.

Chappell, Miles L. "Cigoli's Prospettiva Pratica: Unpublished but not Unknown." In The Treatise on Perspective: Published and Unpublished, edited by Lyle Massey, 105-125. New Haven, CT: Yale University Press, 1997.

Clark, Stuart. Vanities of the Eye: Vision in Early Modern European Cuture. Oxford: Oxford University Press, 2007.

Couchot, Edward. "The Automotization of Figurative Technique: Toward the Autonomous Image." In MediaArtHistories, edited by Oliver Grau, 181-192. Cambridge: MIT Press, 2007.

Daston, Lorraine. "Scientific Objectivity with and Without Words." In Little Tools of Knowledge: Historical Essays on Academic and Bureaucratic Practices, edited by Peter Becker and William Clark, 276-279. Ann Arbor: University of Michigan Press, 2001.

Edgerton, Samuel Y. The Renaissance Discovery of Linear Perspective. New York: Basic Books, 1975.

Gilbert, Bennett. Some Neglected Aspects of the Rococo: Berkeley, Vico, and Rococo Style. MA thesis, 2012. http://search.proquest.com/docview/1562959696.

Gitelman, Lisa. "Introduction." In New Media 1740-1915, edited by Lisa Gitelman and Geoffrey B. Pingree. Cambridge: MIT Press, 2003.

Groebner, Valentin. Who Are You? Identification, Deception, and Surveillance in Early Modern Europe. New York: Zone Books, 2007. 
Harries, Karsten. The Bavarian Rococo Church. Between Faith and Aestheticism. New Haven, CT: Yale University Press, 1983.

Hoff, Hebbel E. and L. A. Geddes. "The Beginnings of Graphic Recording." Isis, 53, no. 3 (1962): 28-324.

Kemp, Martin. The Science of Art: Optical Themes in Western Art from Brunelleschi to Seurat. New Haven, CT: Yale University Press, 1990.

Kittler, Friedrich. Optical Media. Berlin Lectures 1999. Translated by Anthony Enns. London: Polity, 2010.

Lacan, Jacques. Seminar XI: Les quatre concepts fondamentaux de la psychanalyse (Volume 11 of Le séminaire de Jacques Lacan), edited Jacques-Alain Miller. Paris: Seuil, 1973

Lockett, Wilfred G. "Friction According to Jakob Leupold." History of Technology 19 (1997): 47-62.

Manovich, Lev. "The Automation of Sight: From Photography to Computer Vision." In Electronic Culture. Technology and Visual Representation, edited by Timothy Druckrey, 229-245. New York: Aperture, 1996.

Massey, Lyle. Picturing Space, Displacing Bodies: Anamorphosis in Early Modern Theories of Perspective. University Park: Pennsylvania State University Press, 2007.

Minguet, Philippe. Esthétique du rococo. Paris: J. Vrin, 1966.

Parikka, Jussi. What is Media Archaeology? Cambridge: Polity, 2012.

Rink, Evald. "Jakob Leupold and his Theatrum Machinarum." The Library Chronicle, 38, no. 2 (1972): 123-135.

Rothstein, Bret. "Making Trouble: Strange Wooden Objects and the Pursuit of Difficulty ca. 1596." The Journal for Early Modern Cultural Studies 13, no. 1 (2013): 96-129.

Stafford, Barbara Maria. Artful Science: Enlightenment Entertainment and the Eclipse of Visual Knowledge. Cambridge: MIT Press, 1994.

Stafford, Barbara Maria, and Frances Terpak. Devices of Wonder. Los Angeles, CA: Getty Research Institute, 2001.

Tomas, David. Beyond the Image Machine: A History of Visual Technologies. London: Continuum, 2004.

Troitzsch, Ulrich. "Zum Stande der Forschung über Jakob Leupold." Technikgeschichte: Beiträge zur Geschichte der Technik und Industrie 42, no. 4 (1974): 263-286.

Weisgerber, Jean. Le Rococo Beaux-Arts et litterature. Paris: Presses universitaires de France, 2001.

Zielinsky, Siegfried. "Modelling Media for Igtnatius Loyola: A Case Study of Athanasius Kircher's World of Apparatus between the Imaginary and the Real." In Book of Imaginary Media: Excavating the Dream of the Ultimate Communication Medium, edited by Eric Kluitenberg, 28-55. Rotterdam: Nai, 2006.

Zielinsky, Siegfried. Deep Time of the Media. Cambridge: MIT Press, 2008.

Bennett Gilbert, University Studies Program, Portland State University, 117 Cramer Hall, 1721 SW Broadway, Portland, OR 97201, USA. E-mail: bbg2@pdx.edu 